Viewpoint

\title{
Accessibility impacts of high-speed rail
}

\author{
David M. Levinson \\ Networks, Economics, and Urban Systems Research Group, University of Minnesota, Department of Civil Engineering, 500 Pillsbury Drive SE, Minneapolis, MN 55455, USA
}

A R T I C L E I N F O

\section{Keywords:}

High-speed rail

Accessibility

Hub-and-spoke

Network structure

Economic development

\section{Introduction}

High-speed rail lines have been built and proposed in numerous countries throughout the world. The advantages of such lines are a higher quality of service than competing modes (air, bus, auto, conventional rail), potentially faster point-to-point times depending on specific locations, faster loading and unloading times, higher safety than some modes, and lower labor costs. The disadvantage primarily lies in higher fixed costs, potentially higher energy costs than some competing modes, and higher noise externalities. Whether the net benefits outweigh the net costs is an empirical question that awaits determination based on location specific factors, project costs, local demand, competition, and network effects (depending on what else in the network exists). The optimal network design problem is hard (in the mathematical sense of "hard", meaning optimal solutions are hard to find because of the combinatoric possibilities of different network configurations), so heuristics and human judgment are used to design networks.

The network architecture of high-speed rail lines has tended to be in a hub-and-spoke pattern, connecting a hub city (e.g. Paris, Madrid, Tokyo) to secondary cities in tree-like architecture. The networks have occasional crossing links, typically at both lower speed, lower frequency, and lower cost of construction than the mainline. As these systems were designed nationally, and the largest city is often the capital (as in Paris, Madrid, and Tokyo), which is also (roughly) centrally located, it is no surprise that the hub was based where it was. Germany has fewer very high speed links (faster than $300 \mathrm{~km} / \mathrm{h}$ ), and a flatter (less-hubbed) network, perhaps reflecting its strong federalism, relative decentralization into a multi-polar urban structure and late formation into a nation-state. Italy has centered its hub in Milan, the largest metropolitan area in the country.

E-mail address: dlevinson@umn.edu

URL: http://nexus.umn.edu
The reason for the hub-and-spoke architecture is to achieve economies of density in track usage and network effects at the hub city which enable frequent service to multiple destinations. Multiple paths between origins and destinations would diffuse the network effects and result in less frequent service, and therefore reduce demand. The hub-and-spoke architecture, while benefitting the network as a whole when demand is insufficient to enable frequent point-to-point service, clearly serves the hub cities the most, as they gain from all the incoming flows which create additional demand, and thus greater service. In air transportation, airlines often use hub-and-spoke networks, and if they have a large market share at a hub airport, will use that advantage to charge a premium for travel, thereby capturing some, if not all, of the benefits consumers receive from being located in a hub airport city.

\section{Hubs and spokes}

"The spatial impacts of the new lines will be complex. They will favour the large central cities they connect, especially their urban cores, and this may threaten the position of more peripheral cities." (Hall, 2009)

"[T]he wider economic benefits of high-speed rail are difficult to detect, as they are swamped by external factors", but are likely to be larger in more central locations than more peripheral locations." (Preston and Wall, 2008)

As used here, a hub is a center of activity, from which multiple (at least three) spokes (links connecting the hub with other locations) emanate. On a network with a tree structure, the primary hub is the point from which the maximum number of spokes emerge. There may be secondary and tertiary hubs on the network as well.

The proposed US Program (Upper Right of Fig. 1) has no well-thought out national architecture. There were a number of independent proposals that have been drawn on a single map. These can be thought of as hubs (metro area 2010 Census ranking 

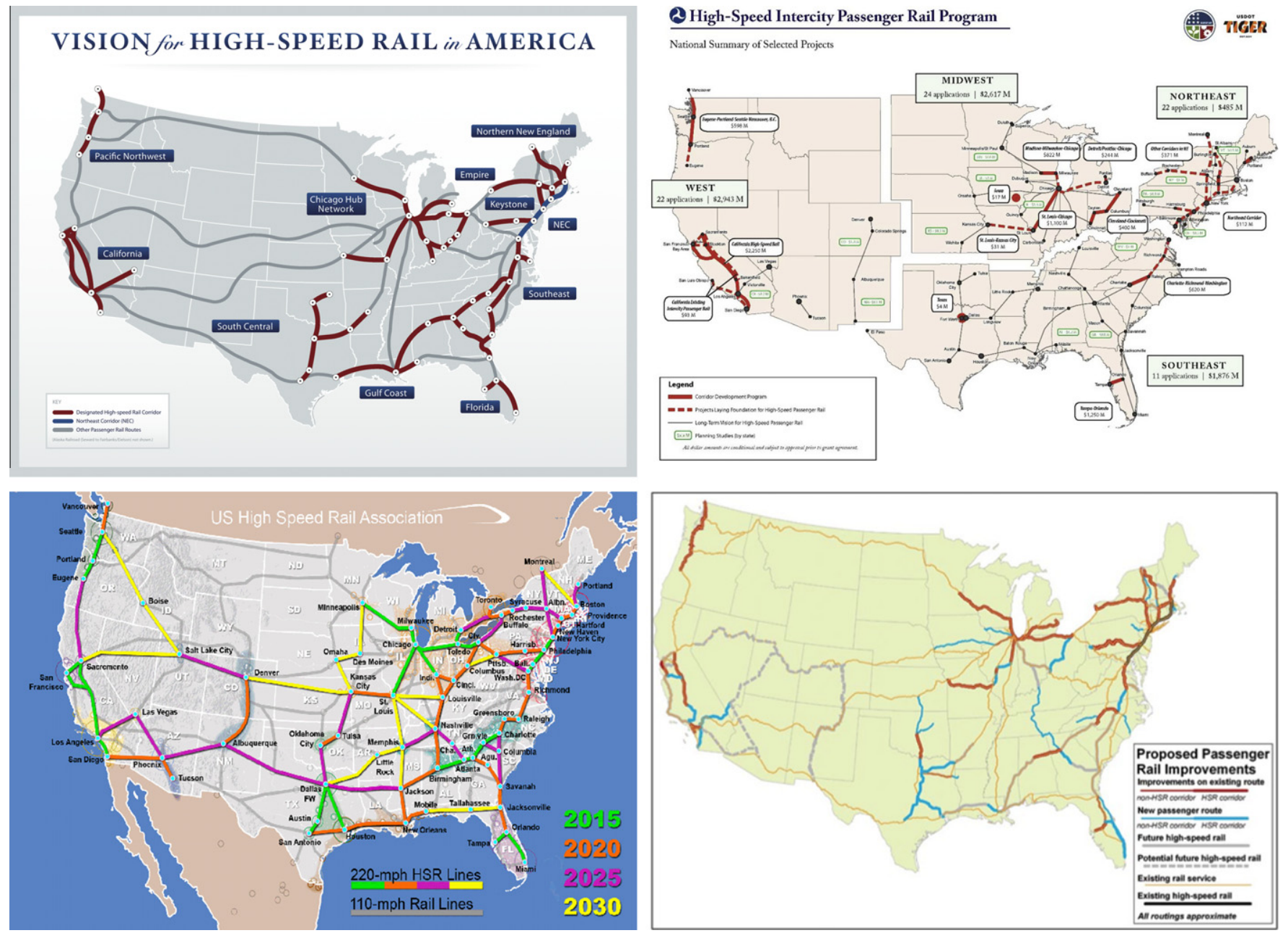

Fig. 1. US HSR proposals: (a) US DOT High-Speed Intercity Passenger Rail Vision, (b) US DOT High-Speed Intercity Passenger Rail Program, (c) US High Speed Rail Association Phasing Map and (d) US Public Interest Research Group. Source: Various.

in parentheses) based in New York (1), Los Angeles (2), Chicago (3), Dallas (4), Atlanta (9), Phoenix (14), Seattle (15), Denver (21), and Orlando (26). ${ }^{1}$ The Florida network (Orlando Hub) has been canceled by the Governor, though in transportation, nothing is permanently dead. The US High-speed Rail Association network includes even more cities.

Several cities tie together multiple hub networks, these include New Orleans (connecting the Dallas and Atlanta networks as the hub of the Gulf Coast Corridor), Raleigh (connecting the Atlanta and New York networks), Louisville (connecting the Chicago and Atlanta networks), and Kansas City (connecting the Dallas and Chicago networks). Those with an eye to drawing networks would easily conceive of links (not yet on the books) connecting Memphis, Nashville, and Knoxville in Tennessee, or Pittsburgh and Cleveland or Columbus. The unofficial advocacy organization, the US Highspeed Rail Association has more comprehensive network plans, including staging, which includes many of these and other links.

These hub networks in the Federal High-Speed Intercity Passenger Rail Program includes the top 47 metropolitan areas of the United States (and many smaller ones), the largest city not in the Program (but apparently in the Vision) is Salt Lake City, Utah, at 50 , with just over 1 million people in the metro area. ${ }^{2}$

\footnotetext{
${ }^{1}$ http://www.en.wikipedia.org/wiki/Table_of_United_States_Metropolitan_ Statistical_Areas.

${ }^{2}$ The next largest city not on the network is Honolulu, Hawaii, at 55.
}

The political genius of the intercity passenger proposal is that it includes lines in all but 8 of the 50 states. $^{3}$ This is a practice learned in transportation from previous national packages, the Interstate Highway System (with miles in all 50 states, including special routes in Alaska and Hawaii) and Amtrak (nearly so), helping ensure strong support in the US Congress, especially the Senate.

Accessibility does two things, first it increases total wealth. Agglomeration economies caused by new infrastructure make aggregate output larger. But second, it redistributes wealth, as the locations where the accessibility gains are larger gain more of that aggregate wealth. Places which do not increase accessibility at least as much as average may find themselves losing economic opportunities which will relocate to take advantage of the accessibility benefits.

Hubs, because of their respective positions, will capture accessibility benefits disproportionate to their already relatively large share of the population. First order beneficiaries are New York, Chicago, Los Angeles, Seattle, and Orlando, as they will be hubs of the new HSR networks. Places where the network branches will also see some benefits, but not as great. Second order beneficiaries are Atlanta and Dallas, which are hubs of the second generation networks. Third order beneficiaries are cities like New Orleans,

\footnotetext{
${ }^{3}$ Alaska, Hawaii, Idaho, Utah, Wyoming, North Dakota, and South Dakota are excluded from the Intercity Passenger Rail Program. However North Dakota and South Dakota have been included in the Minnesota State plan (connecting to Sioux Falls and Fargo).
} 
Kansas City, Louisville and Raleigh which tie together multiple hub networks. Other cities on the networks will also see absolute accessibility gains, people in those cities will be able to reach more people in less time (or with higher quality, or at less outof-pocket cost). However, while they may achieve absolute gains in accessibility, they may lose in relative position, as a greater share of the now larger total accessibility is accumulated by the hub cities.

Network architecture matters a lot, not just in accessibility, but in user travel time. Hatoko and Nakagawa (2007) compare the Swiss railway network and the Japan network, and conclude the mesh-like network with precision timing architecture in Switzerland better serves its population than the hub and spoke mainline system in Japan.

\section{Economic development effects}

There is no grounded empirical work to date on the economic development impacts of high-speed rail in the United States, since such services do not exist. Little has been written from objective (as opposed to vested) sources. The Congressional Research Service has tried to balance the arguments (Peterman et al., 2009).

The job estimates from California ${ }^{4}$ would be enormous if they could be validated. A single infrastructure project creating 450,000 jobs (out of a total civilian employment of under 16 million $^{5}$ ) gives a total of almost $3 \%$ of the state's workforce. The construction related jobs alone are $1 \%$ of the state's workforce. Presently, construction is estimated at 577,000 jobs, so this project would absorb on the order of one-third to one-fourth of all construction jobs in the state.

While the propaganda of project promoters may not be plausible, logically there are some regional effects. An argument could be made about strengthening intercity linkages to refashion the current metropolitan system into a megalopolitan system, where people more regularly interact between cities. One could envision this as Switzerland writ large. If, as Adam Smith suggests, the division of labor is limited by the extent of the market, and transportation can be used to expand the market, the division of labor can therefore increase (i.e. be more specialized), which should have some positive effects for the economy (akin to agglomeration economies). Melo et al. (2009) conduct a meta-analysis of estimates of urban agglomeration economies from 34 studies. The ranges of effects are quite large, and no clear conclusions about the magnitudes can be drawn. The authors write "The findings support the intuition that agglomeration estimates for any particular empirical context may have little relevance elsewhere."

Whether HSR will expand markets depends on whether it is faster (point-to-point) than alternative transportation modes, and on whether it allows users to be more productive. These are both context specific.

Elhorst and Oosterhaven (2008) estimate direct and indirect benefits (additional consumer benefits, indirectly reduced congestion, spatial labor market relocation effects, spatial labor market size and matching effects, and international labor market effects) from a Maglev system proposed for the Netherlands. The indirect benefits range from $0 \%$ to $38 \%$ of the direct benefits.

Interviews with decision-makers at firms in Utrecht, Netherlands, find some firms located to be near the perceived accessibility of urban transit and intercity rail networks, while others were indifferent. However "High-speed trains did not have a significant impact on the location choice of any of the firms" because the advantages over conventional trains were small and connections required transfers anyway (Willigers, 2003).

\footnotetext{
${ }^{4}$ California High-speed rail Authority, "Nearly 160,000 Construction-Related Jobs, 450,000 Permanent Jobs," http://www.cahighspeedrail.ca.gov/news/JOBS_lr.pdf.

5 Source: Bureau of Labor Statistics: Economy at a Glance: California http:// www.bls.gov/eag/eag.ca.htm accessed April 20, 2010.
}

Nakamura and Ueda (1989) (cited in Sands, 1993) finds three of the six prefectures in Japan with a Shinkansen station had higher population growth than the national average between 1980 and 1985, while no prefecture without the Shinkansen grew faster than the national average. Whether the causality is that the rail caused the growth or areas expected to grew attracted investment is unclear. Similar studies conducted of metropolitan growth find results that suggest that Shinkansen and growth are correlated (e.g. Hirota, 1984 reported in Brotchie, 1991), but again the causal structure is not clear. Recent studies suggest the effects of the newer Shinkansen lines are not as favorable as earlier lines (Nakagawa and Hatoko, 2007). Sands (1993) concludes the Shinkansen has shifted growth, but not induced it.

Albalate and Bel (2010) report "Esteban Martín (1998) claims that cities served by High Speed Trains (HSTs) benefit from improved accessibility, but at the same time there is a downgrading of conventional train services and air services on those lines where a HST alternative exists. HSTs do not appear to attract advanced services companies, which show no greater propensity to locate in areas neighboring HST railway stations. And while business tourism and conferences benefit from HST services, a reduction in the number of overnight stays cuts tourist expenditure and the consumption of hotel services. Interestingly, while a HST line improves accessibility between the cities connected by the service, it disarticulates the space between these cities - what has been referred to as the tunnel effect (Gutiérrez Puebla and Garćia Palomares, 2005). Hence, HST lines do not seem to increase inter-territorial cohesion, but rather they promote territorial polarization".

Reviewing the effects in Japan, Europe, and other sites with HSR, Sands (1993), anticipates that "in California, high-speed rail would reinforce existing population and employment patterns and future growth trends." Kim (2000) anticipates that HSR in South Korea will concentrate population in and around Seoul, while it will disperse employment.

While HSR benefits its users, "the high investment in HST infrastructure could not be justified based on its economic development benefits since these are not certain" (Givoni, 2006).

\section{Discussion}

This paper reviews the state of HSR planning in the United States c. 2012. The plans generally call for a set of barely inter-connected hub-and-spoke networks. Several points can be raised.

- There is sometimes a danger of a planner falling in love with his map. There is no danger here, even the same agencies have random maps. It seems as no one cares where the lines actually go, so long as they are high-speed rail.

- The US carries a greater share of freight by rail than Europe. Converting rights-of-way into passenger only (which is required for HSR) may cost some of that freight share.

- Any money spent on HSR cannot be spent on something else. The issue of opportunity costs is seldom mentioned.

- The HSR system in most countries has complemented an existing, serviceable regional passenger rail system, and evolved from that network, replacing elements of existing routes link by link. In contrast, outside the Northeast Corridor and one or two other segments, it is difficult to claim that Amtrak provides a widely used existing conventional intercity passenger rail service. This implies the US system as proposed is not a set of incremental improvements, but a much more significant attempt to jump-start intercity passenger rail. The alternative of incremental, but systematic improvements to the existing Amtrak network has not been seriously considered. 
The evidence from the research shows that lines have two major impacts. There are positive accessibility benefits in metro areas served by stations, but there are negative nuisance effects along the lines themselves. High speed lines are unlikely to have local accessibility benefits separate from connecting local transit lines because there is little advantage for most people or businesses to locate near a line used infrequently (unlike public transit). However they may have more widespread metropolitan level effects. They will retain, and perhaps worse, have much higher nuisance effects than local transit. A previous study of the full costs of high-speed rail in California (Levinson et al., 1997) showed that the noise and vibration costs along the line would be quite significant, even with advanced noise mitigating technologies. The local land use effects at HSR stations are likely to be small to non-existent. Agglomeration benefits may exist, but there is little ground for concluding their size.

If high-speed rail lines can create larger effective regions, that might affect the distribution of who wins and loses from such infrastructure. The magnitude of agglomeration economies is uncertain (and certainly location-specific), but I think presents the best case that can be made in favor of HSR in the US.

True HSR in the US (not the short term improvements to get to 90 or $110 \mathrm{MPH}$, which may or may not be a good thing, but are certainly not high-speed) is a long term deployment, so it needs to be compared with cars 10 or 20 or 30 years hence, and the air transportation system over the same period. Cars are getting better from both an environmental perspective and from the perspective of automation technologies. The DARPA Urban Challenge vehicles, and subsequent development by those engineers working at Google, need to be bested to justify HSR. Cars driven by computers, which while sounding far off, are technologically quite near, and should be able to attain relatively high speeds (though certainly not HSR speeds, in mixed traffic). Further they may move less material per passenger than HSR (trains are heavy), and so may net less environmental impact if electrically powered. These vehicles, which reduce the need for attention from drivers, will likely encourage longer trips by car, which will eat into both rail and air market shares. Aviation is improving as well, both in terms of its environmental impacts and its efficiency. Socially-constructed problems like aviation security or congestion can be solved for far less money than is required for any one high-speed rail line given sufficient will.

\section{Acknowledgments}

This research was funded by New York University. All opinions and errors are those of the author.

\section{References}

Albalate, D., Bel, G., 2010. High-Speed Rail: Lessons for Policy Makers from Experiences Abroad. IREA Working Papers.

Brotchie, J., 1991. Fast Rail Networks and Socio-economic Impacts. Cities of the 21st Century: New Technologies and Spatial Systems, pp. 25-37.

Elhorst, J., Oosterhaven, J., 2008. Integral cost-benefit analysis of Maglev projects under market imperfections. Journal of Transport and Land Use 1 (1), 65-87.

Esteban Martín, V. 1998. La alta velocidad ferroviaria en la Uniǿn Europea. Su impacto urbano en Francia y España. (High Speed Rail in the European Union. Urban impact in France and Spain). Geographicalia 36, 19-32.

Givoni, M., 2006. Development and impact of the modern high-speed train: a review. Transport Reviews 26 (5), 593-611.

Gutiérrez Puebla, J., Garćía Palomares, J., 2005. Cambios en la movilidad en elárea metropolitana de Madrid: el creciente uso del transporte privado. In: Anales de geografía de la Universidad Complutense. No. 25, pp. 331-350.

Hall, P., 2009. Magic carpets and seamless webs: opportunities and constraints for high-speed trains in Europe. Built Environment 35 (1), 59-69.

Hatoko, M., Nakagawa, D., 2007. Comparative analysis of swiss and Japanese trunk railway network structures. In: World Conference of Transportation Research WCTRS.

Hirota, R., 1984. Present situation and effects of the Shinkansen. In: Presented at International Seminar on High-Speed Trains.

Kim, K., 2000. High-speed rail developments and spatial restructuring: a case study of the Capital region in South Korea. Cities 17 (4), 251-262.

Levinson, D., Mathieu, J., Gillen, D., Kanafani, A., 1997. The full cost of high-speed rail: an engineering approach. The Annals of Regional Science 31 (2), 189-215.

Melo, P., Graham, D., Noland, R., 2009. A meta-analysis of estimates of urban agglomeration economies. Regional Science and Urban Economics 39 (3), 332342 .

Nakagawa, D., Hatoko, M., 2007. Reevaluation of Japanese high-speed rail construction: recent situation of the north corridor Shinkansen and its way to completion. Transport Policy 14 (2), 150-164.

Nakamura, H., Ueda, T., 1989. The impacts of the Shinkansen on regional development. In: The Fifth World Conference on Transport Research, Yokohama, vol. 3.

Peterman, D., Frittelli, J., Mallett, W., 2009. High Speed Rail (HSR) in the United States. Tech. Rep., Library of Congress, Washington DC, Congressional Research Service.

Preston, J., Wall, G., 2008. The ex-ante and ex-post economic and social impacts of the introduction of high-speed trains in south east England. Planning Practice and Research 23 (3), 403-422.

Sands, B., 1993. The development effects of high-speed rail stations and implications for California. Built Environment 19 (3), 257-284.

Willigers, J., 2003. High-speed Railway Developments and Corporate Location Decisions: The Role of Accessibility. Paper presented at the 43rd ERSA Congress Jyvaskyla, August 27-30, 2003. 